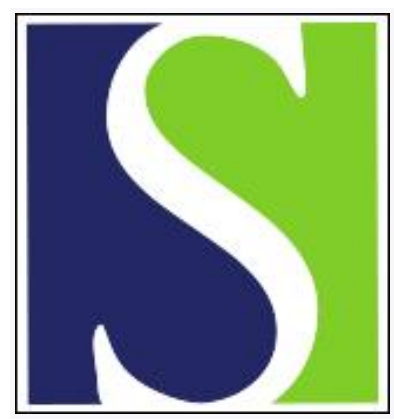

Scand J Work Environ Health 2012;38(6):560-567

https://doi.org/10.5271/sjweh.3292

Published online: 19 Mar 2012, Issue date: 01 Nov 2012

The effect of rest breaks on time to injury - a study on work-related ladder-fall injuries in the United States

by Arlinghaus A, Lombardi DA, Courtney TK, Christiani DC, Folkard S, Perry MJ

Affiliation: Gesellschaft für Arbeits-, Wirtschafts- und Organisationspsychologische Forschung (GAWO) e.V., Achterdiek 50, 26131 Oldenburg, Germany. anna.arlinghaus@gawo-ev.de

Refers to the following texts of the Journal: 2006;32(1):75-84 2011;37(3):173-185

The following articles refer to this text: 2014;40(2):146-155; 2018;44(4):335-339

Key terms: emergency department; fall; fatigue; ladder; occupational injury; occupational safety; rest break; safety; survival analysis; temporal factor; time on task; time to injury; United States; work hour; work scheduling

This article in PubMed: www.ncbi.nlm.nih.gov/pubmed/22430076 


\title{
The effect of rest breaks on time to injury - a study on work-related ladder- fall injuries in the United States
}

\author{
by Anna Arlinghaus, PhD,1,2, 3 David A Lombardi, PhD,1, 2 Theodore K Courtney, MS,1,2 David C Christiani, \\ MD, ${ }^{1}$ Simon Folkard, PhD, ${ }^{4,5}$ Melissa J Perry, ScD ${ }^{1,6}$
}

\begin{abstract}
Arlinghaus A, Lombardi DA, Courtney TK, Christiani DC, Folkard S, Perry MJ. The effect of rest breaks on time to injury - a study on work-related ladder-fall injuries in the United States. Scand J Work Environ Health. 2012;38(6):560-567. doi:10.5271/sjweh.3292
\end{abstract}

\begin{abstract}
Objectives Rest breaks and other work-related temporal factors, such as time spent on task, influence the accumulation of fatigue, and thus impact occupational injury risk. The aim of this study was to investigate the effect of rest breaks on "time to injury" (the time between start of work and injury) for injured workers treated in a nationally representative sample of US emergency departments.

Methods Using the National Electronic Injury Surveillance System (NEISS), we identified 629 workers who had experienced a work-related ladder-fall. Of these, 306 were interviewed by telephone using a standardized questionnaire about the circumstances surrounding the injury. Survival analyses were used to estimate time to injury, and hazard ratios (HR) for time to injury were compared between workers who reported no rest break (reference) and workers who reported rest break(s) prior to the injury (accumulated break time categorized into $0,1-15,16-30$, and $>30$ minutes). Age, gender, time of work start, injury time of day, and workload were included as covariates to control for demographic, circadian, and work-related factors, respectively.
\end{abstract}

Results A clear dose-response relation indicated that longer accumulated break time was associated with a significantly longer time to injury when compared to workers without rest breaks [total break time 1-15 minutes: HR $0.60,95 \%$ confidence interval $(95 \%$ CI) $0.44-0.83 ; 16-30$ minutes: HR $0.50,95 \%$ CI $0.33-0.75 ;>30$ minutes: HR $0.34,95 \%$ CI $0.23-0.51]$, adjusted for all covariates.

Conclusions The results showed that longer total rest break time allowed for a significantly prolonged time spent on task without an injury. These findings suggest that rest break design could be used as a tool to enhance fatigue management and workplace safety.

Key terms emergency department; fatigue; occupational injury; occupational safety; safety; survival analysis; temporal factor; time on task; work hour; work scheduling.

Temporal factors have been linked to the development of fatigue in the workplace, which may lead to performance errors and eventually result in incidents or injuries in the workplace. Circadian and homeostatic factors (such as time of day and time awake) as well as sleep duration and quality have been shown to be related to occupational injury risk [for a review see (1)]. Work-related temporal factors, such as time spent on task, or the number of daily working hours, play a role in the accumulation of fatigue and can influence occupational injury risk (2-7). A crucial factor for injury prevention is the opportunity for rest breaks to allow for adequate recovery from work-related strains, both within the shift and between shifts. While it has been generally acknowledged that the break between shifts needs to be of a minimum length to allow for sufficient rest and sleep [eg, the European Working Time Directive 2003/88/EC (8) includes a minimum

1 Department of Environmental Health, Harvard School of Public Health, Boston, MA, USA.

2 Center for Injury Epidemiology, Liberty Mutual Research Institute for Safety, Hopkinton, MA, USA.

3 Gesellschaft für Arbeits-, Wirtschafts- und Organisationspsychologische Forschung (GAWO) e.V., Oldenburg, Germany.

4 Université Paris Descartes, Institut de Psychologie, Paris, France.

5 Body Rhythms and Shiftwork Centre, University of Wales Swansea, Swansea, UK.

6 Department of Environmental and Occupational Health, School of Public Health and Health Services, George Washington University, Washington, DC, USA 
break duration of 11 hours within a 24-hour period], the effects of rest breaks within a shift on occupational safety have not yet been sufficiently examined. Only a few studies have explored the effect of rest breaks on temporal trends in occupational injuries, and showed that, after a rest break, the injury risk almost returned to the baseline risk level measured at the start of work (9). Additionally, findings in office settings support the beneficial effect of additional short breaks on health and productivity (10-12). However, the preventive effect of rest breaks might differ depending on the work environment (13). Furthermore, the potential for a dose-response relationship between break duration and injury risk has not yet been examined. Gaining more knowledge about these relations would inform prevention strategies, especially with regard to the length of rest breaks, to enhance fatigue management and workplace safety.

The aim of this study was therefore to investigate the impact of rest breaks on "time to injury" (ie, the time between start of work and the injury) in a sample of workers who experienced a work-related ladder-fall injury. The main questions were: (i) are workers who take rest breaks able to work longer without injury than workers who do not take a break? and (ii) does a longer total accumulated rest break time prior to an injury provide a greater protective effect (ie, a longer time to injury) than shorter total break times, suggesting a dose-response relationship?

\section{Methods}

\section{Study sample and questionnaire}

The study sample consisted of workers who were treated in one of 65 participating US emergency departments (ED) after a work-related fall from a ladder. All injury cases were identified and recruited through the National Electronic Injury Surveillance System (NEISS), which is a stratified random sample of all ED visits in the USA. Thus, the injured cases were considered to be a representative sample of all injuries so treated (14). All identified eligible workers were interviewed as soon as possible after their injury via structured phone interview in the time period between September 2006 and October 2008. Of all 629 workers invited for an interview, 306 individuals $(49.3 \%)$ responded and were included in the analysis.

The questionnaire contained 167 items to collect information on worker demographics, injury characteristics and circumstances, work-related factors (ladder and work equipment, work tasks, work environment), temporal factors (injury time of day, day of week, time of start of work and scheduled work end on injury day, amount and timing of rest breaks, working hours in the previous week), and sleep duration and quality in the three nights preceding the injury. Information regarding questionnaire development and content and a detailed sample description can be found elsewhere (15).

The Liberty Mutual Research Institute for Safety Institutional Review Board and the Harvard School of Public Health Human Subjects Committees reviewed and approved the study.

\section{Rest break duration and time into the shift}

Each injured worker was asked "When did you actually take a break(s) on the day you fell?", and start time and duration for each reported break was recorded subsequently (eg, "Break 1 start 10:00 hours, for 15 minutes"). From these records, the number of breaks was enumerated, and the accumulated total break time of all breaks taken prior to the injury was calculated.

Time into the shift (or time to injury, a proxy for time spent on task) was calculated by subtracting the time at which the injury occurred (injury time of day) from the work start time, yielding the number of hours worked until the incidence of the ladder-fall injury. Total reported break time before the injury was subtracted from time into the shift because only the time into the shift that was actually spent working was considered relevant. Work start was measured with the question "When did your work or job start on the day of your fall?". Injury time of day was recorded in response to the question "At what time of day were you injured?". Since in most cases $(\mathrm{N}=278)$ no exact injury time could be recalled, injury time of day was recorded in 2-hour intervals for these individuals, and the average of this time interval was used as the injury time of day (eg, if the response was "injury occurred between 09:00-11:00 hours", injury time of day was coded as 10:00 hours).

\section{Demographic, circadian, and work-related factors}

Age, gender, work start time, injury time of day [categorized into "morning" (06:00-13:59 hours), "afternoon" (14:00-21:59 hours) and "night" (22:00-05:59 hours)], and indicators for workload were included as covariates. Workload and working characteristics were measured with 14 variables and were aggregated with principal factor analysis and subsequent varimax rotation into two factors with Eigenvalues $>1$ named "work demands" (five variables, eg, excessive amount of work, conflicting demands) and "control" (nine variables, eg, decision latitude, learning new things) based on the theoretical model by Karasek (16). 


\section{Statistical analysis}

Descriptive frequencies of demographic characteristics, working conditions, and temporal factors, such as time of day, time into the shift, scheduled work hours, and total rest break time, were calculated. To examine the effects of rest breaks on time to injury, the accumulated break time was categorized into "no breaks", "1-15 minutes", "16-30 minutes", and ">30 minutes" based on the aim of evaluating the effects of a short, medium, and longer overall break time. Thus, the risk of a workrelated injury across time into the shift could be estimated for workers with versus without rest break(s) and within each rest break time category.

To estimate median time into the shift by rest break time, we conducted an unadjusted stratified KaplanMeier analysis $(17,18)$. Cox regression (19) was used to predict survival across time into the shift (eg, the accumulated or cumulative percent of workers without an injury at each time interval), adjusted for age, gender, time of work start, injury time of day categories, work demands, and control. Injury incidence was considered as the event, and time into the shift as the time variable (for the Cox regression categorized in 0.5-hour intervals from $0-\geq 9$ hours), including rest break duration as a covariate. Cumulative survival across time into the shift, hazard ratios (HR), and $95 \%$ confidence intervals (95\% CI) were estimated for breaks versus no breaks and for each rest break category. (The HR is the ratio of the rate at which the event occurs, where a lower HR indicates a longer time of event-free survival.) Due to the study design, all individuals had experienced an injury, thus, the sample contained only non-censored data. Full information on all variables was available for 261 individuals $(85.3 \%)$. All statistical analyses were conducted with SAS version 9.2 (SAS Institute, Cary, NC, USA).

\section{Results}

\section{Demographic characteristics and temporal factors}

The study sample, previously described by Lombardi et al (15), consisted of $263(86 \%)$ men and $43(14 \%)$ women, with a mean age of 38.8 [standard deviation (SD) 13.0] years. The most frequent occupational titles were construction/extraction, installation/repair/maintenance, sales and related, and management (see table 1). Workers were scheduled to work a range from 2-16 hours on the day of their injury, with a mean length of 8.6 (SD 1.7) hours. About 50\% of all workers experienced their ladder-fall injury within the first 4 hours of the shift, and the mean time to injury was 4.6 (SD 2.6) hours.
Among all workers, 145 (49.8\%) reported having had $\geq 1$ rest break during their shift prior to their injury and the accumulated rest times varied in length between 5-90 minutes, with a mean duration of 30 (SD 20) minutes. Of all workers, $110(37.8 \%)$ reported having had 1 break, $25(8.6 \%)$ reported 2 breaks, 9 (3.1\%) reported 3 breaks, and one worker reported 4 breaks prior to their injury; the median number of rest breaks was 1 . Among workers with 1 rest break, reported frequencies of the rest break time categories were $\mathrm{N}=64$ ( $1-15$ minutes), $\mathrm{N}=35$ ( $16-30$ minutes) and $\mathrm{N}=11$ ( $>30$ minutes). Accumulated break time was $>30$ minutes for all workers with $\geq 2$ rest breaks.

Tables 2 and 3 present the distribution of age, work hour characteristics, sleep duration, day of the week when the injury occurred, and working conditions by total accumulated break time. Age, hours worked in the previous week (including overtime), scheduled shift duration, days worked per week, and sleep duration on the night prior to the injury did not differ significantly or systematically between rest break categories, with the exception that workers without any rest breaks were scheduled to work about 1 hour less than workers with $>30$ minutes total rest time (see table 2).

In the earlier hours of the day (ie, between 06:00 14:00 hours), in which most workers were scheduled to work (88.9\%), 225 (73.8\%) of all injuries were reported. Injury frequency in the afternoon (14:00-22:00 hours) and night (22:00-06:00 hours) was substantially lower with $66(21.6 \%)$ and $14(4.6 \%)$, respectively, with $86.6 \%$ and $6.9 \%$ of all workers scheduled to work during that time, respectively. Based on the number of workers scheduled within each time interval, the proportion of injuries was $82.7 \%$ (morning), $24.9 \%$ (afternoon), and $66.7 \%$ (night).

\section{The effect of rest breaks on time to injury}

Unadjusted median times into the shift in each rest break category were calculated using Kaplan-Meier estimation. Workers without rest breaks worked a median of 3.0 hours (95\% CI 2.5-3.5) before the injury, and median time to injury was 3.8 hours (95\% CI 3.3-4.3) for individuals with 1-15-minute break time, whereas workers with longer total rest break time were able to work significantly longer into their workday without an injury (16-30 minutes: 6.0 hours, $95 \%$ CI 5.0-7.0; $>30$ minutes: 6.8 hours, $95 \%$ CI 5.8-8.2).

Figure 1 shows the cumulative survival distributions for injury risk across time into the shift, stratified by accumulated rest break duration, estimated with Cox regression and controlling for age, gender, time of work start, injury time of day, and working conditions. Workers, who reported at least one rest break before the injury, experienced the ladder-fall significantly later in 
Table 1. Distribution of gender, occupational groups, and injury day of the week by total accumulated break time prior to the injury.

\begin{tabular}{|c|c|c|c|c|c|c|c|c|c|c|}
\hline \multirow[t]{3}{*}{ Characteristic } & \multicolumn{10}{|c|}{ Total accumulated break time } \\
\hline & \multicolumn{2}{|c|}{ No breaks } & \multicolumn{2}{|c|}{$1-15$ minutes } & \multicolumn{2}{|c|}{$16-30$ minutes } & \multicolumn{2}{|c|}{$>30$ minutes } & \multicolumn{2}{|c|}{ Total } \\
\hline & $\mathrm{N}$ & $\%$ & $\mathrm{~N}$ & $\%$ & $\mathrm{~N}$ & $\%$ & $\mathrm{~N}$ & $\%$ & $\mathrm{~N}$ & $\%$ \\
\hline Total & 146 & 50.2 & 64 & 22.0 & 35 & 12.0 & 46 & 15.8 & 291 & 100.0 \\
\hline \multicolumn{11}{|l|}{ Gender } \\
\hline Women & 17 & 11.6 & 11 & 17.2 & 3 & 8.6 & 11 & 23.9 & 42 & 14.4 \\
\hline Men & 129 & 88.4 & 53 & 82.8 & 32 & 91.4 & 35 & 76.1 & 249 & 85.6 \\
\hline \multicolumn{11}{|l|}{ Occupation (top 5) } \\
\hline Construction and extraction & 54 & 37.2 & 28 & 43.8 & 19 & 54.3 & 13 & 28.9 & 114 & 39.5 \\
\hline Installation, repair, maintenance & 34 & 23.5 & 14 & 21.9 & 5 & 14.3 & 9 & 20.0 & 62 & 21.5 \\
\hline Sales and related & 11 & 7.6 & 6 & 9.4 & 4 & 11.4 & 9 & 20.0 & 30 & 10.4 \\
\hline Management & 12 & 8.3 & 2 & 3.1 & 1 & 2.9 & 4 & 8.9 & 19 & 6.6 \\
\hline Office and administrative support & 8 & 5.5 & 5 & 7.8 & 2 & 5.7 & 2 & 4.4 & 17 & 5.9 \\
\hline \multicolumn{11}{|l|}{ Day of injury } \\
\hline Monday & 27 & 18.5 & 8 & 12.5 & 5 & 14.3 & 6 & 13.0 & 46 & 15.8 \\
\hline Tuesday & 31 & 21.2 & 11 & 17.2 & 5 & 14.3 & 9 & 19.6 & 56 & 19.2 \\
\hline Wednesday & 29 & 19.9 & 21 & 32.8 & 7 & 20.0 & 5 & 10.9 & 62 & 21.3 \\
\hline Thursday & 23 & 15.8 & 10 & 15.6 & 7 & 20.0 & 8 & 17.4 & 48 & 16.5 \\
\hline Friday & 19 & 13.0 & 9 & 14.1 & 5 & 14.3 & 8 & 17.4 & 41 & 14.1 \\
\hline Saturday & 7 & 4.8 & 5 & 7.8 & 3 & 8.6 & 5 & 10.9 & 20 & 6.9 \\
\hline Sunday & 10 & 6.9 & 0 & 0.0 & 3 & 8.6 & 5 & 10.9 & 18 & 6.2 \\
\hline
\end{tabular}

Table 2. Distribution of age, working hour characteristics, and sleep duration in the night prior to the injury by total accumulated break time prior to the injury [ $95 \% \mathrm{Cl}=95 \%$ confidence interval].

\begin{tabular}{|c|c|c|c|c|c|c|c|c|c|c|}
\hline \multirow[t]{3}{*}{ Characteristic } & \multicolumn{10}{|c|}{ Total accumulated break time } \\
\hline & \multicolumn{2}{|c|}{ No breaks } & \multicolumn{2}{|c|}{$1-15$ minutes } & \multicolumn{2}{|c|}{ 16-30 minutes } & \multicolumn{2}{|c|}{$>30$ minutes } & \multicolumn{2}{|c|}{ Total } \\
\hline & Mean & $95 \% \mathrm{Cl}$ & Mean & $95 \% \mathrm{Cl}$ & Mean & $95 \% \mathrm{Cl}$ & Mean & $95 \% \mathrm{Cl}$ & Mean & $95 \% \mathrm{Cl}$ \\
\hline Age (years) & 38.6 & $36.4-40.7$ & 37.3 & $34.1-40.5$ & 40.6 & $35.6-45.6$ & 40.1 & $36.6-43.6$ & 38.8 & $37.3-40.7$ \\
\hline $\begin{array}{l}\text { Weekly working hours } \\
\text { (hours/week) }\end{array}$ & 40.6 & $38.5-42.6$ & 41.5 & $38.7-44.3$ & 40.1 & $35.3-44.9$ & 40.8 & $37.2-44.5$ & 40.8 & $39.5-42.2$ \\
\hline Days per week & 5.0 & $4.8-5.1$ & 4.9 & $4.8-5.1$ & 4.9 & $4.6-5.2$ & 5.0 & $4.7-5.2$ & 4.9 & $4.8-5.0$ \\
\hline $\begin{array}{l}\text { Scheduled shift length } \\
\text { (hours) }\end{array}$ & 8.4 & $8.1-8.7$ & 8.9 & $8.6-9.2$ & 8.5 & $7.8-9.1$ & 9.3 & $8.8-9.7$ & 8.6 & $8.4-8.8$ \\
\hline $\begin{array}{l}\text { Sleep duration preceding the } \\
\text { injury (hours) }\end{array}$ & 7.4 & $7.2-7.5$ & 7.3 & $7.1-7.6$ & 6.7 & $6.3-7.1$ & 7.3 & $7.0-7.6$ & 7.3 & $7.1-7.4$ \\
\hline
\end{tabular}

their shift than workers without any breaks (adjusted HR 0.49, 95\% CI 0.38-0.63). Furthermore, the results showed a dose-response relationship between time to injury and rest break duration, indicating that longer accumulated break times were associated with a significantly increased time into the shift $(\mathrm{P}<0.05$, risk estimates are presented in table 4).

Additionally, injury time of day was significantly associated with time into the shift (injuries occurred earlier into the shift in the mornings compared to afternoons), but no effect on time into the shift was found for age, gender, work start time, and work-related factors (see table 4). Other variables tested for predictive effects on time to injury were day of the week, working hours in the last week, and sleep duration on the nights preceding the injury, but since no effects were statistically significant, these variables were dropped from the Cox model.

\section{Discussion}

The results of this study on workers who experienced a ladder-fall injury indicated that rest breaks may have an important effect on injury risk. Workers reporting rest breaks worked significantly longer without an injury than workers without rest breaks. Furthermore, a clear dose-response relationship showed that time into the shift without an injury increased substantially with increasing total rest break time.

These results were in line with previous findings showing a beneficial and preventive effect of rest breaks on occupational injuries $(3,9,13)$ and health $(10-12)$. However, only very few studies have explored rest break length effects on safety and performance. One study did not find differences in reaction time between a 15- and 60 -minute break in a driving simulator setting using a 
Table 3. Distribution of work demands and control by total accumulated break time prior to the injury [\%=proportion of workers answering with "agree/strongly agree"; $95 \% \mathrm{Cl}=95 \%$ confidence interval].

\begin{tabular}{|c|c|c|c|c|c|c|c|c|c|c|}
\hline \multirow[t]{3}{*}{ Characteristic } & \multicolumn{10}{|c|}{ Total accumulated break time } \\
\hline & \multicolumn{2}{|c|}{ No breaks } & \multicolumn{2}{|c|}{$1-15$ minutes } & \multicolumn{2}{|c|}{ 16-30 minutes } & \multicolumn{2}{|c|}{$>30$ minutes } & \multicolumn{2}{|c|}{ Total } \\
\hline & $\%$ & $95 \% \mathrm{Cl}$ & $\%$ & $95 \% \mathrm{Cl}$ & $\%$ & $95 \% \mathrm{Cl}$ & $\%$ & $95 \% \mathrm{Cl}$ & $\%$ & $95 \% \mathrm{Cl}$ \\
\hline Job requires working fast & 28.6 & $21.0-36.1$ & 12.5 & $4.2-20.8$ & 26.5 & $10.8-42.1$ & 31.1 & $17.0-45.2$ & 25.6 & $20.5-30.7$ \\
\hline Job requires working hard & 87.9 & $82.5-93.4$ & 93.8 & $87.7-99.8$ & 91.4 & $81.7-100$ & 88.6 & $78.9-98.4$ & 89.7 & $86.1-93.2$ \\
\hline $\begin{array}{l}\text { Not asked to do an excessive } \\
\text { amount of work }\end{array}$ & 83.7 & $77.5-89.9$ & 88.9 & $80.9-96.9$ & 82.9 & $69.7-96.0$ & 86.7 & $76.3-97.0$ & 85.5 & $81.4-89.6$ \\
\hline Enough time to get job done & 87.8 & $82.3-93.3$ & 89.1 & $81.2-96.9$ & 88.6 & $77.5-99.7$ & 93.3 & $85.8-100$ & 89.3 & $85.7-92.9$ \\
\hline $\begin{array}{l}\text { Free from conflicting } \\
\text { demands }\end{array}$ & 78.4 & $71.5-85.3$ & 92.2 & $85.4-98.9$ & 87.9 & $76.1-99.6$ & 86.4 & $75.8-96.9$ & 83.6 & $79.2-87.9$ \\
\hline $\begin{array}{l}\text { Job requires learning new } \\
\text { things }\end{array}$ & 81.6 & $75.1-88.0$ & 90.5 & $83.0-97.9$ & 97.1 & $91.3-100$ & 91.1 & $82.5-99.8$ & 86.6 & $82.6-90.5$ \\
\hline $\begin{array}{l}\text { Job involves a lot of } \\
\text { repetitive work }\end{array}$ & 87.2 & $81.7-92.8$ & 96.9 & $92.5-100$ & 100.0 & .. & 95.6 & $89.3-100$ & 91.4 & $88.2-94.6$ \\
\hline Job requires creativity & 77.4 & $70.3-84.5$ & 85.9 & $77.2-94.7$ & 94.3 & $86.2-100$ & 93.3 & $85.8-100$ & 83.3 & $78.9-87.6$ \\
\hline Job allows own decisions & 78.0 & $71.1-84.9$ & 85.9 & $77.2-94.7$ & 94.3 & $86.2-100$ & 91.1 & $82.5-99.8$ & 83.5 & $79.2-87.8$ \\
\hline $\begin{array}{l}\text { Job requires high level of } \\
\text { skill }\end{array}$ & 87.1 & $81.4-92.7$ & 88.9 & $80.9-96.9$ & 97.1 & $91.3-100$ & 93.3 & $85.8-100$ & 89.6 & $86.0-93.1$ \\
\hline Little freedom for decisions & 20.0 & $13.3-26.7$ & 17.2 & $7.7-26.7$ & 11.4 & $0.3-22.5$ & 11.4 & $1.6-21.1$ & 17.0 & $12.6-21.3$ \\
\hline Variety on the job & 85.8 & $80.0-91.6$ & 95.3 & $90.0-100$ & 97.1 & $91.3-100$ & 95.6 & $89.3-100$ & 90.7 & $87.4-94.1$ \\
\hline $\begin{array}{l}\text { A lot to say about what } \\
\text { happens on the job }\end{array}$ & 70.9 & $63.3-78.5$ & 87.5 & $79.2-95.8$ & 85.3 & $72.8-97.8$ & 88.6 & $78.9-98.4$ & 78.9 & $74.2-83.6$ \\
\hline $\begin{array}{l}\text { Opportunity to develop own } \\
\text { abilities }\end{array}$ & 81.3 & $74.7-87.9$ & 89.1 & $81.2-96.9$ & 94.3 & $86.2-100$ & 95.6 & $89.3-100$ & 86.1 & $82.1-90.1$ \\
\hline
\end{tabular}

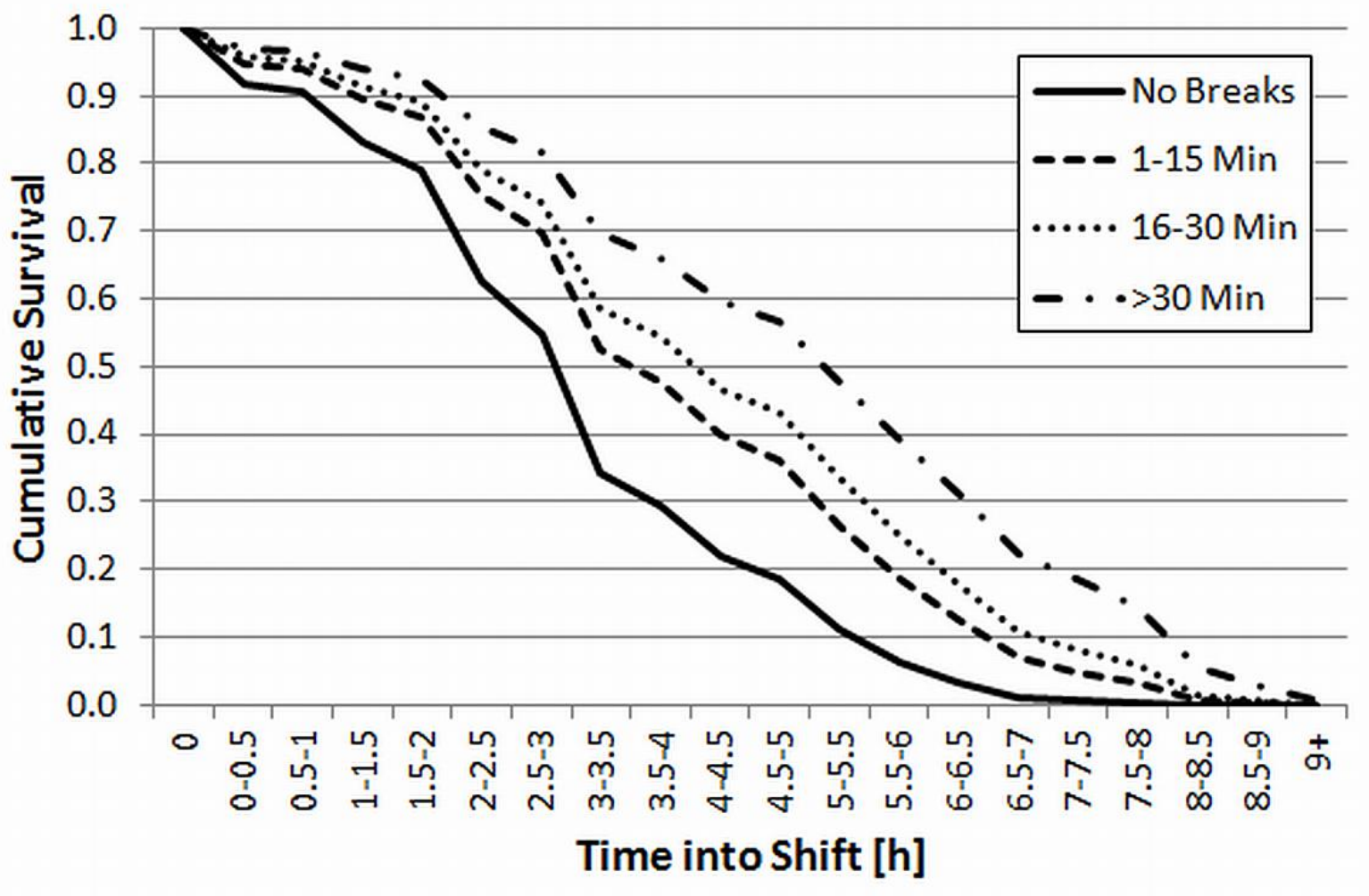

Figure 1. Cumulative survival for individuals without a ladder-fall across time into the shift, stratified by rest break duration. Estimates were calculated with Cox regression, adjusted for age, gender, work start time, injury time of day, work demands, and control. 
Table 4. Parameter estimates, hazard ratios, and 95\% confidence intervals $(95 \% \mathrm{Cl})$ to predict time to injury by rest break duration, using Cox-Regression, controlling for age, gender, work start, injury time of day, work demands, and control.

\begin{tabular}{lcccc}
\hline Parameter & $\begin{array}{c}\text { Parameter } \\
\text { estimate }\end{array}$ & $\begin{array}{c}\text { Standard } \\
\text { error }\end{array}$ & $\begin{array}{c}\text { Hazard } \\
\text { ratio }\end{array}$ & $95 \% \mathrm{Cl}$ \\
\hline $\begin{array}{l}\text { Rest break } \\
\text { duration }\end{array}$ & & & & \\
$\quad$ No break & Referent & & & \\
$1-15$ minutes & $-0.51^{\text {a }}$ & 0.16 & 0.60 & $0.44-0.83$ \\
$16-30$ minutes & -0.70 a & 0.20 & 0.50 & $0.33-0.75$ \\
$>30$ minutes & -1.09 a & 0.21 & 0.34 & $0.23-0.51$ \\
Gender & & & & \\
$\quad$ Women & Referent & & & \\
$\quad$ Men & -0.24 & 0.19 & 0.79 & $0.54-1.14$ \\
Age & 0.00 & 0.01 & 1.00 & $0.99-1.01$ \\
Work start & 0.01 & 0.02 & 1.00 & $0.96-1.05$ \\
Injury time of day & & & & \\
$\quad$ Morning & Referent & & & \\
Afternoon & -1.46 a & 0.19 & 0.23 & $0.16-0.34$ \\
$\quad$ Night & -0.50 & 0.45 & 0.61 & $0.25-1.48$ \\
$\quad$ Workload factors & & & & \\
$\quad$ Work demands & 0.12 & 0.08 & 1.13 & $0.97-1.31$ \\
$\quad$ Control & -0.07 & 0.07 & 0.93 & $0.81-1.06$ \\
\hline a P<0.05. & & & & \\
\hline
\end{tabular}

small sample (20). Another study in an occupational setting (21) demonstrated that introducing a 10-minute rest break after every 60 minutes of work is less tiring than a break of 15 minutes every 90 minutes, consistent with results from earlier studies $(22,23)$. While frequent short breaks seem to show a stronger protective effect than a single long break, more studies are needed to support this finding. Due to limitations in sample size and combinations of break frequency and duration, it was not possible to examine this question further in this study (among workers with one rest break, different accumulated break times were reported, but all workers with $\geq 2$ breaks reported $>30$ minutes total break time, see also results section).

The results showed that workers with start times very early or late in the day did not experience the injury earlier or later into the shift than other workers. In contrast, workers injured in the morning had worked significantly less time until injury than workers injured in the afternoon. One explanation might be that most workers were scheduled to start work in the mornings and, therefore, time to injury by definition was longer for those injured in the afternoon hours compared to those injured earlier in the day. This temporal distribution of injuries and scheduled workers was consistent with an earlier study on occupational traumatic hand injuries (5). Variables like sleep duration and quality on the nights before the injury were also tested and did not affect time to injury, most likely due to lack of variation in the sample (about 70\% reported 7-8 hours of sleep per night). The number of shifts worked prior to the injury might have influenced the effect of rest breaks on injury, but no information on consecutive shifts was available. However, hours worked in the previous week were controlled in the analysis and served as an indicator for the overall exposure.

\section{Limitations and strengths}

Experiencing an injury later into the work shift may increase the likelihood of a worker to have the opportunity for a rest break (or to take longer breaks or several short breaks). This could lead to an overestimation of the protective effects of rest breaks. However, there was no control group with the same amount of breaks without an injury for comparison. For workers experiencing the injury after 7 or 8 hours into the shift (who should have had similar rest break opportunities), longer rest breaks had slightly longer survival times as shown in figure 1, thus longer rest breaks appeared to be protective. Another argument could be that longer break duration increased time to injury per se but break times were subtracted from time to injury for the statistical analyses.

The findings also indicated that workers without rest breaks were scheduled to work 1 hour less than workers with long total break time ( $>30$ minutes), and thus exposure was slightly different. Thus, it could be expected that time to injury would be 1 hour shorter among workers without rest breaks, compared to those with $>30$-minute rest breaks, if rest breaks had no effect on time to injury. However, the difference in median time to injury between these groups was 3.8 hours, indicating a disproportionally stronger effect of rest break time that could not have been caused by a 1 hour shorter shift.

Other limitations include that due to the data being collected within a case-crossover study design (15), only cases were interviewed, thus there is no comparison with a control group of uninjured workers. Additionally, the response rate was not high $(49.3 \%)$, and no information was available to examine differences between the study sample and the non-responders. Furthermore, while the most likely bias in follow-back studies is related to recall (24), recall quality could not be assessed. Since the median lag time between the injury and the followup interview was 34 days, recollection of the exact injury circumstances may have been less precise. It has been shown that recall within 4 days of an injury provides reliable results (24), but in the present study, reliability was not estimated. Although the injured workers were asked to give the time of day in which they were injured, they were given the option of providing a categorical response (eg, 06:00-08:00 hours, 12:00-14:00 hours, etc.). Only 27 individuals were able to give the exact time of the day, therefore the majority was based on 2-hour intervals. In addition, some reports on rest 
breaks were not precise enough to be used (eg, "I had a lunch break but I do not remember the time or duration of the break."). This should not have led to any systematic biases regarding time to injury and rest breaks; however, the times presented should not be regarded as exact hours worked until the injury occurred. The possibility of confounding by unmeasured variables is also possible, for example there may be work environmentrelated factors that influence both time to injury and rest breaks (eg, work pace). However, all workers were matched on task (working on a ladder when injured) and weekly work hours and scheduled shift duration did not differ consistently and significantly between workers with and without a rest break, or between rest break duration categories, indicating no confounding between rest break opportunities and temporal factors. Additionally, the survival models accounted for workload to control for potential confounding, although no workload factor was statistically significant in predicting time to injury. This supports the validity of the findings. However, these results should not be generalized to the overall population of workers, since the occupational groups in this study are characterized by generally hazardous working conditions, and rest breaks might have different effects on injury in other occupations and tasks.

Only about $50 \%$ of all interviewed workers reported $\geq 1$ rest break, and in some cases working long hours without any rest breaks was reported. This leads to the question if the prevalence of rest breaks was low in this sample of injured workers or if this finding was due to imprecise recall of rest breaks. This also implies that the rest time categories chosen here should not be regarded as rigid suggestions for rest break design, but rather as a first attempt to study the dose-response effects of rest break times on time to injury in a field setting. Despite possible inaccuracy in reporting, however, it is unlikely that there would have been systematic recall errors regarding rest breaks depending on time to injury.

On the other hand, the present study has several strengths, such as the use of data from a representative sample of US emergency departments, which were collected with a systematic approach to case-ascertainment (15) and a highly specific case definition. Participants represented a quite homogeneous group mainly consisting of occupational categories such as construction/extraction and installation/repair/maintenance, and included only ladder falls, which decreased the likelihood of confounding by work-related factors or different mechanisms of fatigue and injury.

In conclusion, the results of the present study indicate that taking rest breaks substantially increases time spent on task without an injury, with longer total rest break time showing a higher protective impact than shorter break time. Although fatigue across the shift was not directly examined here, the findings indicate that accumulated work-related fatigue can be at least partially reversed by rest breaks. Thus, these results should be taken into account for future workplace interventions to reduce fatigue and improve occupational safety. Further investigations of optimal rest break duration and distribution using samples with different types of injuries and occupations are needed to increase the validity of these findings and develop strategies for workplace interventions. The recovery effect might also depend on the activity during the break (25); therefore, future studies should collect detailed information about the type of rest breaks (eg, nap, lunch break).

\section{Acknowledgments}

This work was supported by NIOSH (grant number R01 OH-03763), the Center for Construction Research and Training (using NIOSH grant U54 OH008307), and the Liberty Mutual Research Institute for Safety. Dr. Anna Wirtz was funded by a Liberty Mutual - Harvard School of Public Health Postdoctoral Fellowship. The authors would like to thank Dr Helen Marucci-Wellman and Dr Michelle Robertson from the Liberty Mutual Research Institute for Safety for their valuable comments on earlier versions of the manuscript.

\section{References}

1. Williamson A, Lombardi DA, Folkard S, Stutts J, Courtney TK, Connor JK. The link between fatigue and safety. Accid Anal Prev. 2011;34:498-515. http://dx.doi.org/10.1016/j. aap.2009.11.011.

2. Folkard S. Black times: temporal determinants of transport safety. Accid Anal Prev. 1997;29:417-30. http://dx.doi. org/10.1016/S0001-4575(97)00021-3.

3. Folkard S, Lombardi DA. Modeling the impact of the components of long work hours on injuries and "accidents". Am J Ind Med. 2006;49:953-63. http://dx.doi.org/10.1002/ ajim.20307.

4. Hänecke K, Tiedemann S, Nachreiner F, Grzech-Sukalo H. Accident risk as a function of hour at work and time of day as determined from accident data and exposure models for the German working population. Scand J Work Environ Health. 1998;24 Suppl 3:43-8.

5. Lombardi DA, Sorock GS, Hauser R, Nasca PC, Eisen EA, Herrick RF, et al. Temporal factors and the prevalence of transient exposures at the time of an occupational traumatic hand injury. J Occup Environ Med. 2003;45:832-40. http:// dx.doi.org/10.1097/01.jom.0000083030.56116.1a.

6. Nachreiner F, Akkermann S, Haenecke K. Fatal accident risk as a function of hours into work. In: Hornberger S, Knauth P, 
Costa G, Folkard S, editors. Shiftwork in the 21st Century. Frankfurt am Main: Peter Lang; 2000. p19-24.

7. Wagstaff AS, Sigstad Lie JA. Shift and night work and long working hours - a systematic review of safety implications. Scand J Work Environ Health. 2011;37:173-85. http://dx.doi. org/10.5271/sjweh.3146.

8. Directive 2003/88/EC of the European Parliament and of the Council of 4 November 2003 concerning certain aspects of the organisation of working time, Official Journal L 299, 18/11/2003 P. 0009 - 0019 (2003).

9. Tucker P, Folkard S, Macdonald I. Rest breaks and accident risk. Lancet. 2003;361:680. http://dx.doi.org/10.1016/S01406736(03)12566-4.

10. Galinsky T, Swanson N, Sauter S, Dunkin R, Hurrell J, Schleifer L. Supplementary breaks and stretching exercises for data entry operators: a follow-up field study. Am J Ind Med. 2007;50:519-27. http://dx.doi.org/10.1002/ajim.20472.

11. Galinsky TL, Swanson NG, Sauter SL, Hurrell JJ, Schleifer LM. A field study of supplementary rest breaks for dataentry operators. Ergonomics. 2000;43:622-38. http://dx.doi. org/10.1080/001401300184297.

12. Henning RA, Jacques P, Kissel GV, Sullivan AB, AlterasWebb SM. Frequent short rest breaks from computer work: effects on productivity and well-being at two field sites. Ergonomics. 1997;40:78-91. http://dx.doi. org/10.1080/001401397188396.

13. Tucker P, Lombardi D, Smith L, Folkard S. The impact of rest breaks on temporal trends in injury risk. Chronobiol Int. 2006;23:1423-34. http://dx.doi. org/10.1080/07420520601070315.

14. Schroeder T, Ault K. The NEISS sample (design and implementation), 1997 to present. Washington DC: US Consumer Product Safety Commission, Division of Hazard and Injury Data Systems; 2001.

15. Lombardi DA, Smith GS, Courtney TK, Brennan MJ, Kim JY, Perry MJ. Work-related falls from ladders - a follow-back study of US emergency department cases. Scand J Work Environ Health. 2011;37:525-32. http://dx.doi.org/10.5271/ sjweh.3174

16. Karasek RA. Job demands, job decision latitude and mental strain : implications for job redesign. Adm Sci Q. 1979;24:285-308. http://dx.doi.org/10.2307/2392498.

17. Hosmer DW, Lemeshow S. Applied survival analysis. Regression modeling of time to event data. New York: John Wiley \& Sons, Inc.; 1999.

18. Kaplan EL, Meier P. Nonparametric Estimation from Incomplete Observations. J Amer Statist Assn. 1958;53:45781. http://dx.doi.org/10.2307/2281868.

19. Cox DR, Oakes D. Analysis of survival data. London, UK: Chapman Hall; 1984.

20. Lisper HO, Eriksson B. Effects of the length of a rest break and food intake on subsidiary reaction-time performance in an 8-hour driving task. J Appl Psychol. 1980;65:117-22. http:// dx.doi.org/10.1037/0021-9010.65.1.117.

21. Bhatia N, Murrell KF. An industrial experiment in organized rest pauses. Hum Factors. 1969;11:167-74.

22. Jones ED. The Administration of Industrial Enterprises. New York: Longman; 1919.

23. Wyatt S, Fraser JA. Studies in Repetitive Work with Special Reference to Rest Pauses. London: HMSO; 1925. I.F.R.B. Report No.: 32.

24. Lombardi DA, Sorock GS, Lesch MF, Hauser R, Eisen EA, Herrick RF, et al. A reliability study of potential risk factors for acute traumatic occupational hand injuries. Am J Ind Med. 2002;42:336-43. http://dx.doi.org/10.1002/ajim.10120.

25. Gillberg M, Kecklund G, Akerstedt T. Sleepiness and performance of professional drivers in a truck simulator-comparisons between day and night driving. J Sleep Res. 1996;5:12-5. http://dx.doi.org/10.1046/j.13652869.1996.00013.x.

Received for publication: 21 November 2011 